Book Chapter

\title{
Addressing Avoidable Inequalities: The Role of One University in Place- Based Transformational Change
}

Taylor, C., Ruddle, N., Perry, K. and Budden, C.

This book chapter was published in University-Community Partnerships for Promoting Social Responsibility in Higher Education (Innovations in Higher Education Teaching and Learning, Vol. 23. Copyright Elsevier. The definitive version of this article is available at:

\section{Recommended citation:}

Taylor, C., Ruddle, N., Perry, K. and Budden, C. (2020) 'Addressing Avoidable Inequalities: The Role of One University in Place-Based Transformational Change' in Sengupta, E., Blessinger, P. and Mahoney, C. (Ed.) University-Community Partnerships for Promoting Social Responsibility in Higher Education (Innovations in Higher Education Teaching and Learning, Vol. 23), Emerald Publishing Limited, pp. 47 59. doi: 10.1108/S2055-364120200000023004. 


\title{
CHAPTER 4
}

\section{ADDRESSING AVOIDABLE INEQUALITIES: THE ROLE OF ONE UNIVERSITY IN PLACE-BASED TRANSFORMATIONAL CHANGE}

\author{
Claire Taylor, Nina Ruddle, Ken Perry and \\ Clare Budden
}

\begin{abstract}
This chapter explores one UK university's influence and involvement as a key partner within the 2025 Movement, a movement for change with a collective vision to tackle avoidable health and housing inequalities by 2025 in North Wales, UK. The approach to building 2025 is founded in systems leadership and social movements resulting in transformational change in the way we work, think and deliver across a region as a collective. The innovative role of the university as a key partner has shifted the perceptions of the university in the region and its capacity to act as an instrument of government, contributing to the political imperative to support communities as part of the Well-being of Future Generations (Wales) Act 2015. The chapter outlines the principles behind 2025 and the university's role to date, as illustrated through three case studies: Learning and Leadership; Social Prescribing; and Healthy HomesHealthy People. The chapter reflects upon the challenges faced and how they have been overcome. Finally, enablers for successful collective working are identified, which have resulted in the university being able to utilize its expertise, energy and education to work in partnership in order to tackle some of the most complex issues facing our communities.
\end{abstract}

University-Community Partnerships for Promoting Social Responsibility in Higher Education Innovations in Higher Education Teaching and Learning, Volume 23, 47-59

Copyright $(2020$ by Emerald Publishing Limited

All rights of reproduction in any form reserved

ISSN: 2055-3641/doi:10.1108/S2055-364120200000023004 
Keywords: Inequalities; place-based; transformation; change; university; civic engagement; civic mission; community; partnership; leadership

\section{INTRODUCTION}

Wrexham Glyndŵr University was established in 2008 and is located in North East Wales. Its origins can be traced back through the establishment of the North East Wales Institute of Higher Education in 1993, itself a result of a merger of several colleges including the Wrexham School of Science and Art, established 1887. The University is proud of its history of developing higher-level skills and knowledge, working collaboratively to use research and practitioner experience to inform learning and teaching, meet the needs of industry and enrich the different communities that we serve.

The University was established to support the economic and social development of its region, continuing the ethos of its predecessor; indeed, the University's sense of, and contribution to, "place" is critical. In 2018, a Vision and Strategy to 2025 was launched, stating that: "Our mission is to inspire and enable; transforming people and places and driving economic, social and cultural success" (Wrexham Glyndwir University, 2018). Therefore, the regional economic, social and cultural priorities of North Wales and cross-border into North West England inform all aspects of the University's strategy, from its business links to curriculum content.

However, in addition, we also take our civic mission seriously and this is a thread running through the goals and objectives of our vision and strategy. At a primary level, this comprises our core business to provide education, training and research opportunities, which are aligned with current demand and which prepare our graduates to be able to function and contribute in a world that may look very different in future decades. We are also aware of the resource we can offer to the community, sharing knowledge and being generous with our time, in a way that goes above and beyond strict requirements of the curriculum. It is this aspect of our mission that is explored in this chapter.

Our civic engagement strategy sets out our key focus to become a civic university, that is, transformative, responsive and demand led. We set out to achieve this by working in partnership across the region on the shared ambition to support the growth and resilience of people and communities to achieve economic, social and cultural success. Within this there is a strong focus on being visionary, to respond to the drivers for change by pioneering new approaches, responding to public service austerity innovatively and rethinking the space that universities traditionally occupy. Therefore, we are using our experience and expertise and role as "educators" to explore new and different ways of working and delivering change on a number of levels.

The civic engagement strategy is shaped around five main overarching aims, with associated actions and projects to drive delivery against each area:

- Leadership of place.

- Active citizenship.

- Support schools and young people. 
- Innovation and social capital.

- Enable, engage and develop the civic mission.

A key thread running through is the focus on leadership of place, supporting and leading projects across the region and nationally through the establishment of partnerships with a range of organizations and sectors. In particular, a partnership with leadership practice, Do-Well (UK) Ltd (http://www.do-well.co.uk/) has been a catalyst for our innovative approach to public service leadership education and practice. This organization provides strategic, policy and practical support to a range of public and third-sector organizations and working with Do-Well has enabled the University to draw on both practical and current leadership experience and challenges that we have married with the principles of our civic engagement strategy to really drive and support change across the region and wider. Although three specific case studies are outlined in this chapter, through this partnership the University has supported with expertise and resource a number of projects. For example, the Let's Get Moving North Wales (NHS Wales, Public Health Wales, 2018) campaign is bringing partners together to improve health and well-being of the population of North Wales, through increasing opportunities for people to move more. We are also a key partner in Sports North Wales, a new partnership approach to rethinking community sports commissioning and delivery across the region. We have facilitated and led the visioning sessions and helped shape the approach to drive innovation across all sectors. We have developed a strong partnership with local Community Voluntary Councils across the region, supporting a sub-regional approach to volunteering and ensuring we maximize the impact and provide higher-level qualifications in partnership. Supporting schools and young people is a strategic focus for Welsh Government and we are leading a key part of a pan-Wales approach to supporting school governors and leaders with systems leadership in partnership with the Open University, Cardiff University and Higher Education Funding Council. In addition, the University is represented on a number of key national and regional projects that enable and drive our civic mission including the Regional Centre of Expertise Cymru. Through this we are leading on Social Prescribing as part of a network of organizations that facilitate learning toward sustainable development in local and regional communities and this is part of a global learning space for sustainable development (RCE Cymru, 2018).

Overall, the University is working within an established strategy for civic engagement, with clearly identified themes and objectives. Collaborative working and active partnerships are essential for success and underpin the University's focus on leadership of place, supporting and leading place-based projects across the region and nationally.

\section{THE CHALLENGE: TACKLING INEQUALITY}

Inequality is one of the biggest collective challenges faced across the UK (RSA, 2018) and is a particular issue for North Wales, where people living in the most 
deprived areas are expected to live around 13 fewer years than those people living in the least deprived (NHS Wales, Public Health Wales, 2017). This evidence, coupled with an increasing focus on social determinants of health inequalities (Marmot, 2015), plus the drive of leaders across regional civic society and public services framed the collective challenge across the region - to identify and tackle avoidable inequalities faced by individuals and communities across North East Wales.

In 2014, a social movement called 2025 began in North Wales to tackle this complex challenge, created by a small group of leaders across housing, health and local authority services. The University joined the 2025 Movement in 2017, recognizing that action needed to be taken. It was also timely for the University as the Welsh Government outlined a new vision for reinventing the civic mission of universities (Higher Education Funding Council for Wales (HEFCW), 2018). Also uniquely, Wales is the first country globally to legislate for improving the social, economic, environmental and cultural well-being of the nation, through the ground-breaking Well-being of Future Generations (Wales) Act 2015 (Future Generations Commissioner, 2015). Therefore, these key political and social imperatives provided an ideal context for a "social movement."

The pioneering founders of 2025 wanted to tackle inequality with a fresh and different approach that cut across sectors, organizations, behaviors and cultures, taking significant personal and professional risks through developing a new approach in a highly regulated setting that was innovative and not "compliant" in the current systems and organizations in which they worked. Therefore, the 2025 Movement has become an innovative, place-based partnership with a clear mission to end avoidable health inequalities in the region by 2025 (2025 Movement, 2015).

Harnessing "systems leadership" (The Leadership Centre, 2016) has been the key to growing the movement, leading to long-term transformational change in the way we work, think and deliver across the region. In learning to lead across boundaries - between organizations, departments, sectors or places - a more sustainable, long-term approach to large-scale transformational change is possible, driven by collective responsibility rather than single points of disconnected isolation.

\section{5: WORKING IN THE GAPS}

The approach to building 2025 as a social movement was founded upon wanting meaningful social change unhampered by system and organizational boundaries (Moyers, 2014). This meant a focus on "working in the gaps" - spaces where organizations were not working together effectively to drive change. As a result of this work, the movement now brings together senior leaders and practitioners across a range of organizations covering social housing, local authorities, police and fire services, Public Heath Wales, the regional health board and Wrexham Glyndwor University. All partners hold a shared belief that the collective wanted to do something that could help tackle the "avoidable" health inequalities - recognizing that some inequalities are less, or not, avoidable, but 
taking action through the systems leadership principle of starting somewhere and doing something.

A "Just Do Teams" (JDT) approach was developed in 2016/17 once the challenge was clear. "JDT" were formed around the areas of concerns or growing need, driven by key people from different organizations to test and pilot different approaches. The level of the leaders for each JDT did not matter and the way the JDT developed and focused was also not prescriptive. The main focus was to drive collective action, working together to make a positive difference to the priority areas, which were identified as:

- Place-based regeneration in Flintshire.

- Healthy Homes-Healthy People.

- Mental health and housing.

- "Made in North Wales" Social Prescribing.

- Learning and Leadership.

- Tackling health inequalities for homeless people.

- Facilitating improvements in hospital discharge.

- Adverse childhood experiences.

The following case studies illustrate the University's role across three of the priority areas: Learning and Leadership; Social Prescribing; and Healthy HomesHealthy People.

\section{CASE STUDY 1: LEADING AND LEARNING TOGETHER THROUGH A CO-CREATED PUBLIC SERVICE LEADERSHIP PROGRAM}

The political, social and economic imperatives of increasing demand on public services, coupled with decreasing resources and "wicked problems" (Grint, 2008), which are novel and intractable, demand new ways of thinking, working and collaboration. Therefore, as the 2025 Movement gained momentum, Wrexham Glyndŵr University recognized the significant impact that a systems leadership approach (Atkinson, Loftus, \& Jarvis, 2015) was having on the coalition. This approach focused on leadership across departmental, organizational and sectoral boundaries, through influence and facilitation. The University recognized the need for senior leaders across the coalition to support and nurture a new wave of future leaders able to work in a whole systems approach through a professional development program.

In designing a development program the University looked to mirror the five ways of working outlined by the Wellbeing of Future Generations Act (Future Generations Commissioner, 2015). This legislation required a number of public bodies and organizations to work together in ways that had not been explored before. The five ways of working have at their heart the need to maintain a longterm rather than purely short-term view of the issues to be tackled and proposed solutions. In addition, ways of working have to integrate approaches across 
different bodies, involve people, act collaboratively and work in a way that seeks to prevent problems from occurring in the first place.

Therefore, in the context of the Wellbeing of Future Generations Act (Future Generations Commissioner, 2015) it was important that the University promoted a co-created approach for developing the curriculum. This was done through stakeholder engagement sessions and discussions with key influencers to explore the potential and appetite across sectors, levels and professions for an education program focused on tackling the key challenges of working across boundaries. The engagement was done on a number of levels including with housing associations, private-sector organizations and third-sector organizations. The ambition was for a leadership program to be co-created and "owned" by all those who shaped and informed the content, ensuring long-term and sustainable leadership focused on tackling the challenges faced across all sectors. This engagement culminated in the University hosting a Leadership and Learning 2025 conference in April 2018 with over 120 delegates and a key focus to:

- understand the context and priorities across North Wales and how, through leadership and learning, we can collectively tackle the complex issues faced across all sectors;

- explore how the 2025 Movement influences and supports public leadership and the aims of the Wellbeing of Future Generations (Wales) Act 2015;

- understand the business case for investment in learning and public leadership from the perspective of the private and third sectors; and

- create opportunities for engagement in the co-creation of a public service leadership program.

The University developed and delivered a pilot "taster" session of Systems Leadership with the Inspiring Resilient Communities Group (Flintshire Public Service Board, 2017) for a number of professionals from different sectors and professions. As a result of this, the University committed to delivering a full module for those willing to progress, to introduce the concept and theory of systems leadership. We delivered a short course 20 credit module "Introduction to systems leadership". Learning outcomes focused on the need and context for change, foundations for systems theory, knowing and navigating the difference between management and leadership, the foundations for building personal and community resilience and approaches to working across whole systems. Thirteen students completed this pilot program in early 2019 and it has had positive feedback, especially in relation to work on developing public narratives (Ganz, 2012), a leadership practice that helps develop powerful stories to motivate others to join in action. The feedback from the pioneering cohort and co-creators has had a significant impact:

I've been on loads of courses in the past... I know the theory inside out... but this is different - this isn't about theory it's about what you practically can do, and that's the big difference I've found. (Senior Manager, Local Authority A)

In the public sector because of austerity and because of resources becoming more scarce, there is a real need to have a programme that will bring future leaders and current leaders together. 
I think working in partnership is the only way forward to deliver better public services. (Senior Officer, Local Authority B)

After the programme people will continue to work together and in the future we'll see people moving across sectors more easily - and that can only be a good thing, developing more transferable skills. (CEO Housing Group)

Following the short course, the University now plans to develop a full Masters level program in Public Service Leadership. The program will be designed with accessibility and flexibility in mind, reflecting feedback from the pilot sessions. In this respect, component parts will be delivered as shorter standalone modules to address a particular challenge or focus on certain issues. The program will have contributions from current, future and past key leaders and change makers from across the region and beyond. Key to success will be the alumni support network, generated through program participation. When students are back in the "systems" in which they work, the University (working with JDT) will support students to apply and develop systems leadership approaches and techniques from the course. This will in turn support further development of the place-based program as it evolves and helps transform public services across Wales. In this way, a network of like-minded leaders is developing across the region, equipped to facilitate change across boundaries and confident to work energetically "in the gaps" in order to transform lives and communities.

\section{CASE STUDY 2: "MADE IN NORTH WALES" SOCIAL PRESCRIBING}

A "JDT" was established to develop a "Made in North Wales" Social Prescribing project supported by the 2025 Movement, Wrexham Glyndŵr University and Betsi Cadwaladr University Health Board (BCUHB). BCUHB is the largest health board in Wales, caring for a population of over 700,000 people, with responsibility for a full range of primary, community, mental health and acute hospital services (NHS Wales, 2019). The partnership is a response to the challenge of how we reimagine health services, shifting from paternal models of care through the National Health Service (NHS) delivered by BCUHB for empowering people to take control of their own healthcare choices and to engage them in local community activities with a focus on prevention and well-being. The key challenge is an evolving evidence and research base that means the approach is currently only piloted across the region. It is not funded by core NHS budget and therefore attracts varying level of adoption by clinicians. In addition, there are varying levels of funding for smaller schemes focused within the third sector that have little impact if not connected on a regional level to share and capture learning.

Social prescribing is a local, regional and national challenge recognized by the Future Generations Commissioner (2019) in Wales as a national key policy priority as one approach to relieving pressures on the NHS and moving away from an over medicalized model of care. As such, the University has worked with the 2025 Movement and the Well North Wales program in BCUHB across the region 
to initiate the project, shape and develop its focus and define the model for future delivery, capturing and sharing models as they grow to address local demand for supporting improved health and well-being. As a University, we are leading the Community of Practice $(\mathrm{CoP})$ network for practitioners, and we are also leading the development of a co-created education framework to support delivery, starting with a Social Prescribing module.

The CoP was established in October 2018 funded by the civic mission monies secured by the University from the HEFCW. It provides a wider platform for sharing across Wales, connecting with other CoPs and also being a partner in establishing a collaborative bid for an all Wales Institute for Social Prescribing Research. This is a long-term sustainable model that brings together key practitioners from across a range of background together to try and develop, improve, connect and share practice related to Social Prescribing. To date over 200 practitioners have attended the $\mathrm{CoP}$ and this will grow moving forward, with a number of future networking events planned to grow the learning community.

Alongside the CoP initiative, we have developed and delivered a short course to a cohort of 10 Social Prescribing practitioners. The aim of the pilot, funded by HEFCW as part of the University's civic mission focus, was to look at how a Social Prescribing certificate delivered by the University could ensure there is a level of education that supports the implementation of a new model of health and well-being across the region, therefore providing confidence and consistency in this model. The purpose of piloting the short course with practitioners was to provide a focus and evidence base to demonstrate how education and a learning community can influence the thinking and approach to delivering and embedding a new and evolving model of Social Prescribing across the region.

Practitioners that attended the course were from a range of professional and sector backgrounds: clinical, non-clinical, link workers, social workers, community development officers and volunteers, sports officers, mental health charity officers, third sector officers and local authority and health board staff from across the whole geographical region. The course provided significant feedback that has led to some key actions as a result. Practitioners recognized real value in the educational approach and the need to undertake a formal module, particularly to build credibility in the model and to recognize the number of roles that support "Social Prescribing" given the varying titles/roles and different settings. The opportunity to network and understand different models supported learning and reflection, highlighting the need to recognize local responses to local needs and challenges that can vary across the region. As an outcome from the feedback the University is now developing different levels of education in Social Prescribing from a short one hour master class to raise awareness to a Masters level qualification.

\section{CASE STUDY 3: HEALTHY HOMES- HEALTHY PEOPLE}

The "Healthy Homes-Healthy People North Wales" JDT focuses on creating healthy homes, people and communities by removing residents from fuel poverty, 
improving health and well-being, and reducing avoidable health inequalities. Over 3,000 vulnerable homes have been identified across the region where families are living in cold, damp or unsafe homes which affect their health, safety and wellbeing. Those living in private-sector rented accommodation in particular were often falling in between "services" for support for fuel poverty, therefore widening the inequality gap and missing out on access to support (Warm Wales, 2018). Conversely, those living in owner-occupied accommodation or living as tenants within council or housing association provision subject to robust regulation generally had support from landlords or access to personal resources to address or tackle this issue.

Led by Flintshire County Council in partnership with North Wales Energy Advice Centre, Ground Work North Wales, and Care and Repair North East Wales, initially the focus was on Flintshire, a local authority area. The project quickly moved into a regional approach due to the impact and success, funded by Warm Wales and by Wales and West Utilities. The project involved home visits to support households referred from agencies and partners as those vulnerable to or at risk of fuel poverty. Referrals came from organizations such as housing associations, local authorities, primary healthcare providers and third-sector organizations offering health and well-being services. Visits involved looking at four key areas: home and personal/family safety; money maximization; family and personal support; and affordable energy looking at the best tariff for heating to reduce costs, helping with debt and energy efficiency methods. As a key partner in this initiative, the University supported the project with student volunteers from the BSc Mental Health and Wellbeing program. Students volunteered their time to attend home visits which were then accredited as work placement learning. The focus of each home visit was to engage, encourage, educate and empower individuals and families in order to support them to take control and make changes and access support where needed.

The University's work with the 2025 Movement on the Healthy HomesHealthy People project has been featured in the Universities UK report "The Nation's Lifesavers" (Made at Uni, 2019), a focus on the exceptional 100 universities working to keep Britain healthy. The impact of the project has been recognized further with the project manager being awarded "Heat Hero" in the House of Commons. This project shows the direct impact that a university working in partnership with students and organizations can have, both in providing innovative student learning opportunities and in demonstrating its civic mission in action, in this case through having a positive impact on fuel poverty and inequality across wider society in North Wales.

\section{CHALLENGES FACED}

Wrexham Glyndwrr University has been active at the heart of the 2025 social movement, demonstrating civic engagement in practice. The three case studies outlined previously show notable successes and considerable impact over a relatively short time, but this has not been without its challenges for the University 
and the wider 2025 network. For example, initial challenges were received from organizations that did not understand the approach and the structure of an informal partnership to drive change. Traditionally, public-sector bodies and even many third-sector organizations in the UK operate with a focus on hierarchical decision-making and governance structures, which are counter to an approach founded upon systems leadership. Systems leadership is an "art" approach to change making and not a "science." It is founded in ways of feelings, perceiving, thinking, relating, doing and being, where strong relationships and trust are key (Atkinson et al., 2015).

Initial challenges around the approach used were overcome by supporting this different form of leadership development through short course provision and mentoring (facilitated by Do-Well) that developed a commitment and energy from individuals and organizations. Key to this commitment was the existence of a good understanding from all partners of the collective challenge being faced and the need to test and drive change through working in new ways together on a regional level. Critically, opening up membership of 2025 to any organization or individual meant that the network was inclusive and accessible.

There was also a need to acknowledge the inevitable clash between "new power" values, embodied in the development of an informal network marked by self-organization, collaboration, agility, wide participation and transparency and the "old power" which is traditionally formal, managerial, institutional, competitive and reliant on experts and specialists with long-term affiliation and less overall participation (Heimans \& Timms, 2018). Individuals and organizations were challenged to understand the drivers and concepts of the 2025 Movement that could clearly be explained by contrasting the old and new power values, although it is important to note that it was not a case of one being good and one bad, but that they are different and have a different role to play in society. The creation of fora for open discussion and debate such as the CoP for Social Prescribing and the systems leadership short course provided safe spaces in which to consider these issues.

There was even some skepticism about the new approach which led to a number of individuals in senior organizational roles challenging the establishment and purpose of the movement - perhaps because of a perceived loss of control. The adaptive leadership approach (which systems leadership draws upon) recognizes that people fear loss more than they fear change for a number of reasons (Heifetz, Grashow, \& Linsky, 2009). For some, there may have been a fear of loss of perceived "status" or lack of control/governance or accountability to an informal partnership such as 2025 tackling a complex challenge. In order to address this, the movement promoted an open and inclusive invitation to all. Anyone interested in or sharing the same challenge could come along and join, resulting in the creation of a critical mass of people from across the region committed to seeing change.

There was also need to develop a proof of concept to evidence that the approach could work by "JDT" working on projects. This was achieved through the first annual report of the coalition (2025 Movement, 2018) which recognized and articulated the different organizational and cultural needs and requirements to drive change and to mobilize and grow the movement. Through a series of case studies commonly structured to cover project aim, costs, work to date, challenges, 
successes, learning and work to do, the report represents a powerful evidence library with regard to the performance and effectiveness of the 2025 Movement and the JDT concept in particular.

\section{SUCCESS ENABLERS}

Early success on key projects was galvanized through highly successful, thought provoking and well-managed conferences disseminating ideas around key themes. These gained a lot of support quickly across the region and developed a wider membership for the movement. It was recognized that movements don't just "happen," and that a strong structure, good organization, focus and parity in approach of partners around the table were essential. In this respect, key partners, including the University all equally contributed a modest financial sum to provide support for conference organization and "JDT" program management. This has proved to be a sound structure for connecting and reporting key projects and ideas but also for promoting equity around the table, supporting a dispersed leadership approach (Atkinson et al., 2015) through varying levels from Chief Executive Officers to project managers.

The key to the whole success of the movement and the future growth is the resilience and drive of senior leaders to persist particularly in the early days of its development. The bravery and the boldness of leaders such as the 2025 Chair and the independent facilitation of Do-Well cannot be under estimated. This approach was new and challenged the approaches in current systems and some of the "thinking" of how we should work in public service and across sectors.

A key challenge to any social movement is resourcing activity but the University was able to secure funding from $\mathrm{HEFCW}$ directly linked to civic mission activity and this has been a significant success enabler in the first 18 months of our engagement with 2025 (HEFCW, 2018). Importantly, the funding has enabled the University to create a role that leads on civic engagement strategy, connecting with partners from across public, private and third sector to identify and explore key opportunities and projects that can help tackle the challenges faced. By securing a dedicated role, the University is able to demonstrate commitment to being an active partner in place-based transformation.

On a national scale, the political driver that exists in the Wellbeing of Future Generations Act should not be under estimated. The Act provides an excellent context to support and ensure the growth of the University's engagement with its civic mission and to support the work of 2025 in particular. In tackling the global challenge of sustainable development the legislation has not only helped support the "case" for the content of the work being done with 2025 but it also directly delivers on the five ways of working embodied within the Act to collaborate, integrate, involve, prevent and ensure a long-term approach (Future Generations Commissioner, 2015). The Healthy Homes-Healthy People project is a good example of the five ways of working in practice. This project tackling fuel poverty would not have made the wide connection to Social Prescribing, with the Health Board and University without 2025. This would have led to 
University students not being able to take advantage of an innovative, impactful and real-world learning scenario through work placement opportunities.

2025 across the region has been a force for good and driver for change, highlighting the power of a collaborative cause that can influence whole systems change. The movement has rapidly established a reputation for filling a void in the multi-agency health inequalities agenda across North Wales, and not with just the "usual" delivery agencies. Most importantly though, all the projects, including the three highlighted in this chapter that illustrate University involvement, are wider than the remit of the lead or organization. Rather, the network, built upon connections and relationships, is a key success enabler for influencing on change both on and within systems and organizations. An extensive conference and workshop program has been an important factor in disseminating good practice, forging new working relationships and enhancing the scope of individual projects. 2025 has been the catalyst to enable these programs to collectively thrive, extend and succeed, demonstrating that the overall success really is greater than the sum of the individual parts.

\section{CONCLUSION}

The 2025 Movement continues to grow in partners, priorities and success, and is ideally placed to provide a regional platform for delivering impactful prevention activities and projects in North Wales. Key has been a shared vision, a strong set of values and a vibrant network that has strengthened the connectivity and impact of the project and the way of working across the region. The University is a dedicated and committed partner to the 2025 movement and our civic engagement strategy sees ongoing work with 2025 as an important vehicle for tackling our very real regional challenges. The innovative role of the University as a key partner has shifted the perceptions of the University in the region and its capacity to act as an instrument of Government, contributing to the political imperative to support communities as part of the Well-being of Future Generations (Wales) Act 2015. In reinventing its approach to civic mission, the University is working collectively on some of the most complex issues facing our communities, using our resource, expertise, energy and education to work in partnership (Goddard, Hazelkorn, Kempton, \& Vallance, 2016). In particular, through expanding our educational program of whole system change that has been created and is "owned" by partners we are keen to ensure the approaches exemplified in this chapter can be emulated and extended, creating a real force for transformation for the benefit of individuals and communities locally, regionally and nationally.

\section{REFERENCES}

2025 Movement. (2015). 2025 Movement. Retrieved from https://2025movement.org/ 2025 Movement. (2018). 2025 Movement first annual report. Unpublished manuscript. Atkinson, J., Loftus, E., \& Jarvis, J. (2015). The art of change making. London: The Leadership Centre. 
Flintshire Public Service Board. (2017). A well being plan for Flintshire 2017-2023. Retrieved from https://www.flintshire.gov.uk/en/Resident/Council-and-Democracy/Flintshire-Public-ServicesBoard.aspx

Future Generations Commissioner. (2015). Future Generations Act. Retrieved from http:// futuregenerations.wales/about-us/future-generations-act/

Future Generations Commissoner. (2019). Future Generations Act priority areas. Retrieved from https://futuregenerations.wales/fgcw-priority-areas/

Ganz, M. (2012). Public narrative, collective action. Retrieved from www.marshallganz.usmblogs.com

Goddard, J., Hazelkorn, E., Kempton, L., \& Vallance, P. (2016). The civic university: The policy and leadership challenges. London: Edward Elgar Publishing Ltd.

Grint,K.(2008).Wickedproblemsandclumsysolutions. Retrievedfromhttp://leadershipforchange.org.uk/ wp-content/uploads/Keith-Grint-Wicked-Problems-handout.pdf

Heifetz, R., Grashow, A., \& Linsky, M. (2009). The practice of adaptive leadership: Tools and tactics for changing your organization and the world. Brighton, MA: Harvard Business Press.

Heimans, J., \& Timms, H. (2018). New power. How it's changing the 21st century- and why you need to know. New York, NY: Macmillan.

Higher Education Funding Council for Wales. (2018). Circular-enhancing civic mission and community engagement. Retrieved from https://www.hefcw.ac.uk/documents/publications/circulars/circulars_ 2018/W18\%2007HE\%20Enhancing $\% 20$ civic\%20mission $\% 20$ and $\% 20$ community $\% 20$ engagement. pdf

Made at Uni. (2019). Lifesavers made at uni. Retrieved from https://madeatuni.org.uk/wrexhamglyndwr-university/addressing-avoidable-inequalities

Marmot, M. (2015). The health gap: The challenge of an unequal world. London: Bloomsbury.

Moyers.(2014). MarshallGanzonmakingsocialmovementmatter. Retrievedfromhttps://billmoyers.com/ segment/marshall-ganz-on-making-social-movements-matter/

NHS Wales. (2019). Betsi Cadwalader University Health Board. Retrieved from https://bcuhb.nhs. wales/

NHS Wales, Public Health Wales. (2017). North Wales geographical level information. Retrieved from http://www.wales.nhs.uk/sitesplus/888/page/87493

NHS Wales, Public Health Wales. (2018). Public Health Wales - Let's get moving North Wales. Retrieved from http://www.wales.nhs.uk/sitesplus/888/page/92311

RCE Cymru. (2018). The sustainability lab. Retrieved from http://planet.cymru/en/wales-rcewcfg/\#tab1

RSA. (2018). Britain's new giants. Retrieved from https://www.thersa.org/discover/britains-new-giants

The Leadership Centre. (2016). The revolution will be improvised part II. Retrieved from https://www. thinklocalactpersonal.org.uk/_assets/News/The_Revolution_will_be_Improvised_Part_II.pdf

Warm Wales. (2018). Healthy homes healthy people North Wales project. Retrieved from https://www. warmwales.org.uk/healthy-homes-healthy-people/

Wrexham Glyndŵr University. (2018). Wrexham Glyndŵr University vision and strategy to 2025. Retrieved from https://www.glyndwr.ac.uk/en/media/156309\%20Strategy\%20English.pdf 